\title{
LA CULTURA COMO PRODUCTO DE FICCIÓN
}

\author{
Antonio LóPEZ-CRUZ \\ I.E.S. Jacarandá
}

Resumen: En su VIII Oda Pítica, el poeta griego Píndaro describe al hombre como "sueño de una sombra". Reconocemos que esta visión del hombre, inspiradora de formas distintas de idealismo, es fundamentalmente una visión poética, una metáfora forjada bajo la luz de la conciencia del infinito que impregna a todos los seres humanos que se sienten parte de un todo inabarcable que los contiene. Y no podemos dejar de reconocer también que, como otras formas metafóricas, es tan sumamente esclarecedora como para llevarnos a admitir que, si bien la noción de "ser humano en el mundo" es problemática, es aún más problemática la posibilidad de considerar reales nuestras producciones mentales.

Palabras clave: ficción, realidad, racionalidad, privilegio, ser humano.

Abstract: In his Pythian Ode VIII, the Greek poet Pindar describes the man as the 'dream of a shadow'. We recognize that this vision of man, which inspires various forms of idealism, is fundamentally a poetic sight, a metaphor forged under the light of the consciousness of infinite that overwhelms all human beings feeling as part of an incomprehensible whole. And we cannot fail to recognize as well that, like other metaphorical forms, is so extremely inspiring as to lead us to admit that while the notion of 'being human in the world' is problematic, it is even more problematic the possibility of considering our mental productions real.

Keywords: fiction, reality, rationality, privilege, human being. 
"[...] en breve espacio crece la dicha de los mortales. E igual de pronto cae por tierra, zarandeada por un designio ineluctable. ¡Seres de un día! ¿Qué es uno? ¿Qué no es? El hombre es el sueño de una sombra. Mas cuando llega un rayo de luz enviado por Zeus, un resplandor brillante le distingue entre las gentes y su existencia es gozosa [...]"

Píndaro, VIII Oda Pítica

\section{ALEGORÍA SOBRE LA CONDICIÓN HUMANA}

Comencemos recordando la célebre historia del tan ingenuo como presuntuoso gallo que, haciendo honor a su condición, cantaba todos los días al amanecer. Esto lo colmaba de dicha infinita. Mientras amanecía y él cantaba, se sentía protagonista y testigo privilegiado de un suceso imponente; así transcurrió su existencia, lleno de dicha y ennoblecido cotidianamente con el maravilloso acontecimiento. Sin embargo, un día tuvo lugar una singularidad que por natural no dejó de turbar de forma dramática la existencia del crédulo animal.

Sucedió que una mañana el gallo se quedó dormido en su acogedor lecho de paja, y cuando despertó, sobresaltado, comprobó aterrado que, a pesar de no haber cantado esa mañana, el sol se había alzado, y frente a él lucía una espléndida mañana, tan luminosa como sólo pueden serlo las mañanas de verano.

Fue sólo entonces cuando comprendió aquello que instantes después le haría poner fin a su vida: el sol no se levantaba en el horizonte gracias a su canto, el astro ignoraba la existencia de la modesta ave, de su canto al amanecer; este era un acontecimiento al margen de su existencia. Descubrió que toda su vida había carecido de sentido y su existencia también carecía de él.

No pudo soportar ese hecho. Lo que hasta esa mañana le había parecido un fastuoso acontecimiento producido por el indescriptible don de su canto quedó reducido a la vulgaridad de un acontecer mecánico, natural.

En ese instante, sin dilación, el gallo hizo que su corazón dejara de latir.

\section{BOSQUEJO GRONOLÓGICO DE LA FICGIÓN OCCIDENTAL}

El conocimiento elemental nos dice que el ser humano y su mundo están llenos de complejidades, estas tienen su origen en que uno y otro son pensados por el propio ser humano, son fruto de su propio pensamiento en la medida en que este media con la realidad. Esta mediación consiste en intentar desentrañar el enmarañado entramado de relaciones tejidas por el lento transcurrir de un tiempo sin medida.

El nacimiento y la muerte son sucesos no mediados por el pensamiento, tienen lugar al margen de su categorización, al margen del simbolismo con el que los queramos revestir. Por el contrario, el matrimonio, la patria, el estado, la economía financiera, la justicia... son categorizaciones que el ser humano elabora. 
Clásicamente esto se ha planteado en términos de oposición entre la naturaleza y la cultura. En nuestro planteamiento lo expresaremos en términos de realidad y ficción.

Entenderemos por realidad aquello que contiene todo acontecer, sea este humano o no, y el acontecer mismo, antes de ser tamizado por una conciencia.

Por ficción entenderemos todo acontecimiento pensado, categorizado, simbolizado, pasado a través de la criba del pensamiento. En sentido filosófico, tal y como aquí entendemos la ficción, esta no es una mímesis de algo preexistente denominado realidad; las ficciones no son las sombras de entidades atemporales y sustanciales, tampoco se trata de realidades conscientemente fingidas para producir mundos alternativos. Tal y como lo entendemos, la ficción es la realidad propiamente humana, elaborada, construida por el ser humano, para habitarla como humano, alejándose de una naturaleza hostil y desposeída de espíritu. Así expresado, podemos afirmar que la cultura, la sociedad, la ciencia, el mundo humano, son ficciones. Para el humano la única realidad que puede ser entendida es aquella que ha sido transformada en ficción.

Esta ficción es el resultado de un elaborado proceso creador, desarrollado a lo largo del tiempo, de un tiempo que sólo es dilatado en cuanto que humano y que en términos culturales es todo el tiempo. Este tiene su origen en la capacidad simbólica por la que se caracteriza la humanidad y que queda materializada en el lenguaje. Esta capacidad simbólica es el germen de toda ficción, ya que, como elemento sustitutivo, el símbolo crea una realidad alejada del origen, alejamiento que aumenta en la medida en que el símbolo necesita de la convencionalidad para instalarse como universal cultural. Esta distancia fruto de la convencionalidad se convierte en sideral cuando el propio símbolo es trasmitido por aprendizaje a miembros de generaciones posteriores.

Dadas estas circunstancias, confundir la realidad con su expresión simbólica es razonable cuando no inevitable. La cuestión deriva en problema cuando quienes están sujetos a esta confusión son o deberían ser conscientes de ella, dado que además de vivir en un mundo simbólico son creadores activos de él. Filósofos, científicos, sacerdotes, políticos, financieros, etc.

El símbolo nos permite pensar en lo no presente, nos permite habitar el ámbito temporal, crear el pasado así como proyectarnos en el futuro, dimensiones exclusivamente humanas, puras ficciones legitimadoras de estructuras explicativas del mundo.

\section{PRELUDIOS DE NUESTRA CULTURA:DEL CANDOR A LA INOCENCLA}

Más allá de las posibles interpretaciones psicoanalíticas, siempre tan atractivas y con infinita capacidad explicativa, atribuiremos las diversas formas de estructuración del mundo, elaboradas a través del tiempo, a la conmovedora inmadurez humana sometida sin la menor resistencia a elevadas dosis de soberbia que empujan a éste a considerarse privilegiado. 
Prueba de la dotación privilegiada será en los primeros momentos la capacidad imaginativa, apta para elaborar universos mitológicos cuya deslumbrante fantasía incapacita cualquier atisbo crítico. Contradictoriamente, el orden cósmico queda sometido a la arbitrariedad de fuerzas oscuras, impenetrables, ingobernables sin límites explicativos.

La fantasía, en la que se fundamenta este recién inaugurado mundo, es poco exigente consigo misma a la hora de buscar explicaciones justificativas, aunque su producción es ilimitada, no satisface la necesidad de predicción exigida por el ímpetu dominador, ni establece un orden cósmico suficientemente estable. Las entidades míticas están dotadas de voluntad propia y las relaciones entre ellas tienen un fundamento antropomórfico que dificulta que la recién inaugurada ficción (mundo) pueda ser clausurada, finita, controlable. Es demasiado fluida, poco acogedora en cuanto que inestable, incluso errante. Este mundo nativo carece de homogeneidad, de tranquilizadora necesidad referencial.

A pesar de su gran capacidad descriptiva, de estar apegada al devenir de la experiencia, se presenta como inquietante, desasosegadora para sus creadores. Paulatinamente, la exigencia de consistencia, permanencia y seguridad se troca en obligación.

Surgen asílos grandes relatos, anclados enla objetivación, en la sustancialización de lo eterno, que pretenden fundamentar originariamente la realidad humana; son discursos legitimadores estructurados y articulados racionalmente y que, posteriormente, en especial a partir de la ilustración, la contemporaneidad los denominará metarrelatos.

Tanto los grandes relatos como los metarrelatos tienen como finalidad delimitar, totalizar, dar verosimilitud a la ficción, elaborar un mundo en el que el ser humano sea "ser orientado".

Los grandes relatos pretenden prescindir de la imaginación originaria creadora de mitificaciones. Es sólo una pretensión, puesto que la nueva facultad creadora de ficción, la razón, en su fundamento último carece de anclaje al margen del mito. Esta razón actúa como maquinaria de sometimiento a distintos criterios de orden. Elabora un modelo de mundo que garantiza la estabilidad, la unidad, la eternidad de lo preexistente, el aval de lo sobrenatural. Llamativamente, la garantía de orden, de racionalidad, se fundamenta en el más allá, en lo ajeno al mundo, a lo natural, a la sustancia misma.

Distintas formas se han utilizado para denominar y ocultar este fundamento del mundo racional. Sin duda la más persistente en el tiempo ha sido la de Dios, la ficción de las ficciones en la medida en que sólo es aprehensible a través de una forma de sofisticación de la imaginación que los creadores de grandes relatos denominan fe.

La razón originaria se impondrá la colosal tarea de crear el cosmos entendido como totalidad sometida a un orden intrínseco, al que someterá al mundo para 
justificar la existencia humana como realidad privilegiada dentro de un todo hostil para un ser indefenso pero con "mal carácter".

En los primeros momentos de la razón balbuceante, esta se muestra con debilitada determinación a la hora de crear ficciones utilizando sus recursos, se hacen concesiones a la recién denostada imaginación y aparenta tener algunas contradicciones frente a la autoridad de los sentidos, pero poco a poco la fascinación que suscita se irá imponiendo.

Los sentidos, a pesar de ser nuestra única conexión con el medio, con lo otro, no son suficientes para colmar las ínfulas de una especie insaciable, son capacidades puramente fisiológicas compartidas por el resto del reino animal; en comparación, los sentidos humanos aparecen como mediocres, limitados tanto en la precisión como en el alcance. A esto se añade que nos muestran un mundo confuso, nos desvelan una realidad fracturada, compuesta de teselas desprovistas de configuración predeterminada, que, desconectadas entre sí, sumergen al hombre en el devenir ingobernable y el caos.

La razón comienza su actividad creadora afianzándose como la nueva facultad refrendadora del privilegio humano frente al resto de seres vivos, se funde con la facultad imaginativa a la que fagocitará y metabolizará dando lugar a una nueva forma de explicación cuyo objetivo inicial es marcar distancias frente a las explicaciones míticas. Para ello, elabora un procedimiento que establece el marco de acción de la recién estrenada facultad, que limitará su poder explicativo e instaurará un único procedimiento de verificación de la verdad. En este momento nace la lógica, una nueva ficción, fruto de la metafísica racionalista, que presupone la existencia de leyes intrínsecas a la propia razón capaces de garantizar la coherencia, que actuará como garantía de la facultad que a partir de ese momento creará el mundo, partiendo de la premisa de que este se sitúa frente a ella inmóvil, imperecedero, preñado de esencias sustancializadas que obedecen a un orden interno que se corresponde con el que emana de la razón. Se acaba de crear un nuevo mito, el mito de la razón.

\section{AFIRMACIÓN DE LA CULTURA: DE LA INOCENCIA A LA INGENUIDAD}

A lo largo de los siglos, la narrativa racional va urdiendo un conjunto de mitos con diversos objetivos. Unos actuarán como herramientas de la pretenciosa nueva facultad, como es el caso del concepto o la definición, otros como coartada: realidad, esencia, sustancia o causa; y otros como finalidad: la verdad, el conocimiento, la justicia u otros. Todos estos mitos se desarrollan paralelamente, crecen con lentitud, intentando establecer una distancia cada vez mayor en relación a procedimientos explicativos más originarios e intuitivos como la mitología primitiva que, carente de sometimiento a la necesidad, ofrecía una ficción menos acogedora. La nueva ficción, la razón, el nuevo mundo fruto de 
ella, se totaliza frente a la fragmentación anterior; la nueva realidad, envolvente, maravilla al hombre. Su asombro frente al orden establecido por la ley natural lo afianza en la convicción de un mundo real. Tanta perfección, armonía, ajuste, es la prueba concluyente (homo ingenuo) de que el ser humano ha abandonado para siempre el mundo ficticio. El ser humano vislumbra la utopía: ubicarse en una realidad estable, cognoscible que pueda ser definitivamente sometida. Una utopía en la que definitivamente el ser humano se constituya en ser hegemónico. Esta arrogancia, que puede llegar a ser conmovedora, ha acompañado al ser humano desde su constitución y ha irrigado todo proyecto, toda acción humana. Lo humano no es solo opuesto a lo natural, sino que se sitúa en un plano más elevado, alejándolo de lo puramente biológico; esta arrogante fantasía es la que posibilita lo humano. Sin ficción solo seríamos biología. El símbolo, la abstracción mediada por el lenguaje, es lo que nos dota de humanidad; habitamos en la ficción, el símbolo nos separa de la atadura de la naturaleza. Con la ficción, transformamos y fabricamos la realidad habitada. El humano es ficción encarnada, materializada en una biología de la que a su vez emana como elemento liberador de lo puramente natural.

En la razón, el hombre cree haber encontrado su genuina naturaleza, todo será reducido a ella con sistemática determinación, se desata un frenesí racionalizador que en ocasiones muestra la candidez con la que el ser humano se ha enfrentado a su existencia, candidez que contrasta con la altivez propia de la especie. Prueba de todo ello es el convencimiento de que la historia, entendida como conjunto de aconteceres inmersos en el tiempo, también obedece a un orden de regularidades, de leyes objetivables en un corpus coherente que la razón puede desentrañar. Poco a poco, la racionalidad se extenderá a todos los ámbitos, y aquellos donde se instaura adquieren carácter de madurez y solvencia.

No obstante, la realidad sensible demanda su protagonismo, los sentidos informan, facilitan datos que deben ser integrados en el nuevo orden de la razón, aunque en muchas ocasiones la información sensible y los argumentos de la razón aparezcan como contradictorios. Frente al inmovilismo y la objetividad de la razón, los sentidos dejan constancia de un mundo cambiante, propio de cada uno, subjetivo en la medida en que los umbrales sensitivos son tan diversos como los individuos existentes. Aunque la razón es monolítica e impone sus criterios organizativos, los sentidos son tenaces y se desvelan como fuente originaria de no ficción antes de ser doblegados a la integración perceptiva. De nuevo la razón impondrá sus premisas, los sentidos serán sometidos a sus determinaciones enarbolando el principio de objetividad, la medición, la magnitud, la proporción matemática y el método serán sus grandes aliados para este dulce sometimiento. Nace así una nueva forma mitológica y fuente de ficción, la ciencia. 


\section{FORTALECIMIENTO DE LA CULTURA: DE LA INGENUIDAD A LA INCONSCIENCIA}

Consideramos que debemos prestar una atenta mirada a esta nueva forma de fabricar mundo que es la ciencia, ya que en ella se dan particularidades desconocidas hasta este momento histórico.

Efectivamente, la ciencia, tal y como se plantea a partir del Renacimiento y, sobre todo, cuando alcanza su madurez en el siglo XVIII con Isaac Newton y entendida como conjunto de datos sistematizados, sometidos a un lenguaje universalmente aceptado, el lenguaje matemático, y provista de una lógica interna que le ofrece consistencia, ofrecerá al hombre un nuevo motivo de autocomplacencia: mientras que las explicaciones racionales, como hemos afirmado, han sido capaces de crear un mundo clausurado, definido, ordenado, gobernable, con fisuras asumibles por la propia razón, sin embargo, estas explicaciones pertenecen a un cosmos paralelo, alejado de lo empírico, puramente ideal, que tiene su origen y su final en la conciencia humana. La ciencia, a diferencia de la pura razón, aludirá al universo perceptivo. En ella confluyen la razón y los sentidos, y ambos, mediados por el lenguaje matemático, caracterizado por no tener referentes ajenos al propio lenguaje, es decir, puramente formal, gestado en una razón "auto-referenciadora" y que se ha erigido en paradigma de racionalidad, van a ofrecer una nueva forma de explicar el mundo. A partir de este momento, los acontecimientos son explicados mediante observaciones y hechos que están supeditados a las leyes racionales, conectadas lógicamente entre sí, dando lugar a teorías con un mayor poder explicativo que las primeras y que, siguiendo el mismo principio de orden lógico, se organizan en estructuras a su vez más amplias, originando sistemas más poderosos a la hora de dilucidar los acontecimientos. Finalmente, estos sistemas, nuevamente organizados, dan lugar a aquello de lo que se ha partido y que posibilitó la elaboración de las leyes iniciales a partir de las primeras observaciones: los paradigmas científicos. Estos son modelos teóricos de la realidad que, si bien se nutren de informaciones sensibles, estas no solo están enormemente alejadas de ellos, sino que, están considerablemente condicionadas por el modelo teórico que pretenden explicar.

El grado de complejidad de esta organización de datos que denominamos ciencia, puede - o deberíamos decir debe-ser garantía de seguridad en relación al grado de fiabilidad de los resultados, y, con seguridad, a esto responde su elaborada estructura; sin embargo, todo el entramado científico descansa, además de en las informaciones aportadas por los sentidos, en dos disciplinas puramente racionales, apriorísticas. La ciencia presupone que estas disciplinas tienen un referente externo que responde a los mismos principios de orden de los que ellas parten: la matemática y la lógica. Disciplinas ambas puramente formales que, si bien en sus fundamentos renuncian a explicar el mundo empírico, son utilizadas justamente para ello. 
Los que consideramos que la razón no es más que una forma de mitología, de creación de mundo, generadora de ficción, en la medida que su finalidad es pretender dar una explicación de lo que previamente se ha definido como realidad, consideramos que el más elemental principio de cautela nos obliga a poner bajo sospecha a la propia ciencia.

A pesar de todo lo dicho, debemos reconocer que la ciencia tiene un gran aliado a la hora de elaborar argumentos que desmonten los brevemente expuestos: la efectividad.

El ser humano es un ser ávido de autoafirmación, buena parte de nuestra trayectoria intelectual ha estado destinada a confirmar la veracidad de lo imaginado, de lo creado. Lo más destilado del intelecto humano, por llamativo que pueda parecer, ha dedicado sus mejores esfuerzos a la confirmación de prejuicios originados a partir de las más variadas ideologías y creencias. En este sentido, la efectividad de la ciencia, y posteriormente la tecnología, supone un hito y un combustible inagotable para alimentar la vanidad humana y su pueril autoafirmación. Esta efectividad se manifiesta espectacularmente en pequeños ámbitos de lo socio-natural, en parcelas bien delimitadas y estrechamente conectadas con lo empírico; sin embargo, cuando nos vamos alejando de esa inmediatez, cuando referimos lo puramente empírico a conceptos, cuando vamos elevando el nivel de abstracción de esos conceptos y los relacionamos con otros de su misma categoría lógica, la efectividad de las previsiones y la validez de los resultados alcanzados van disminuyendo de manera llamativa. De ahí que la ciencia tenga que utilizar marcos explicativos, paradigmas, que se caracterizan por su provisionalidad, y que la razón científica considere que esta es uno de sus rasgos definitorios.

Nuevamente nos encontramos con la dificultad de cerrar el círculo racional, a la hora de elaborar explicaciones universales que parten apriorísticamente de supuestos imaginarios que pretenden corresponder con lo que la realidad es. Y es que la realidad humana, como venimos afirmando a lo largo de toda nuestra exposición, no es otra cosa que ficción, la creación de una mente, la humana, necesitada de respuestas ante un cosmos autista, silente. La comunicación con la totalidad, con la naturaleza, es otra de las muchas ensoñaciones de una especie como la humana, cuyo voluntarismo le lleva a creer que el hecho de considerar que la naturaleza debe responder a nuestras preguntas hará que efectivamente lo haga, que considera que, partiendo de una definición de realidad, hará que esta exista efectivamente y que, suponiendo que la razón es una facultad poderosa frente al objeto de conocimiento, lo será.

Consideramos que conceptos como realidad, conocimiento, verdad, razón no son más que conceptos auto-referenciales, que una vez que abandonamos ese marco de referencia no son más que formas vacías, estériles, inapropiadas para dar una explicación en relación "a lo que pudiera haber". Cuando no se reconoce esta exclusiva validez auto-referencial, cuando la racionalidad, ya sea científica, 
lógica o metafísica, se enroca y pretende monopolizar las explicaciones sobre el mundo en el que nos hallamos arrojados, se está poniendo de manifiesto la consideración, igualmente vacua, de que la especie humana goza de algún tipo de privilegio dentro de este distante todo.

La Modernidad, primero, y la Ilustración, después, profundizarán en este soliloquio egocentrista, desarrollando discursos monocordes y excluyentes que monopolizan cualquier tipo de posible explicación frente a la totalidad.

En el caso del planteamiento moderno, el único garante mundano de todo posible conocimiento es situado en un epicentro conceptual denominado Yo. Este concepto, que se nos muestra como elemento fundacional de secuencias argumentativas, es producto de una mente con gran potencial fantástico, dado que, aunque es un concepto que se refiere a lo universal, se hace perfectamente compatible con encarnaciones individuales y operativas que en el plano teórico son sustancialmente idénticas. Este recurso racional de fundamentar las particularidades empíricas en conceptos universales que carecen de existencia real, que "habitan" exclusivamente en cosmos ideales, puramente imaginarios, es utilizado por las explicaciones racionalistas, que sistemáticamente declaran huir de cualquier atisbo de mitologización, con una normalidad que contrasta con su exigencia crítica y con la profundidad y el rigor que constantemente se les atribuye para distinguirlas de otro tipo de explicaciones consideradas fantásticas.

El Yo moderno no es un concepto menos fantástico que otros muchos a los que no se les concede estatus racional y, por tanto, son inválidos a la hora de ofrecer explicaciones sobre aquello que denominamos realidad. Cuando la modernidad se nos plantea como uno de los paradigmas de la racionalidad (en contraposición con lo fantástico, con lo irreal, con lo ficticio), obviando las consideraciones que acabamos de hacer sobre ella, no tenemos que olvidar que, si bien el Yo es el concepto central, no es el fundacional, ya que este Yo universal, para ser creíble, para poder fundamentar con el rigor necesario, necesita de un garante, cuya existencia como realidad descansa, al igual que él, exclusivamente en su propio concepto. Como bien sabemos, ese garante es el más fantástico de todos los conceptos, el mito originario y fundador de todos los grandes mitos, Dios.

El Dios de la Modernidad es tal que, como en otros períodos de la historia del pensamiento, su existencia es fundamentada en una supuesta necesidad lógica y metafísica, como si la necesidad fuese algo inherente a la totalidad, en vez de ser un concepto que nuestra imaginación impone a una forma particular de ver el mundo. El hecho de suponer, de imaginar, que a la totalidad le corresponden características que la definen, es una constante que muestra cómo la imagen preeminente del mundo es tan ficcional como cualquier otra que se haya podido elaborar en otro periodo u otra cultura. Cualquier tipo de cosmogonía, elaborada en cualquier período histórico, ya sea esta mítica, puramente racional 
o científica, tiene su origen en la imaginación humana, como no puede ser de otra forma, dado que es la capacidad creativa la única que puede enfrentarse a una totalidad muda con la exigencia de obtener una respuesta.

La Ilustración será el resultado de la euforia provocada por el enardecimiento del Yo en la Modernidad, junto a un desbordante optimismo, propio de la clase burguesa que veía crecer su bienestar vital, así como su consolidación como clase dominante.

La razón, como característica esencial del Yo fundador, y el adiestramiento de esta mediante los distintos métodos, hacen de ella un instrumento de consolidada eficacia que no encuentra límites a sus distintas aplicaciones.

En este período, como sabemos, se considera sobradamente establecido que la realidad y la ficción son dos opuestos claramente delimitados, por lo que el interés se centrará fundamentalmente en las formas de aproximarnos a eso que llamamos realidad. No obstante, también sabemos que, en el momento en el que la exigencia de fundamentación del proceso cognoscitivo demanda rigor, nos topamos con la imposibilidad de definir con claridad aquello sobre lo que trata ese mismo proceso, la propia realidad. En este momento, se utilizan términos sucedáneos que se refieren a ese objeto de conocimiento; términos como noúmeno, de una infinita opacidad racional, pero que puede ser perfectamente entendido a través de la imaginación, que una vez más se convierte en el garante de comprensividad de la totalidad en la que estamos inmersos.

La razón ilustrada, fertilizada por un desbordante optimismo, dará lugar a la idea de progreso que veteará todos los grandes planteamientos explicativos sobre la totalidad en este período. El progreso se convierte así en una idea directriz de la razón, encaminada a dar cuenta de una totalidad que se considera que ha salido para siempre del "humillante" yugo del mito y del dictado de la "pueril" imaginación de la humanidad. La razón, la intelectualidad de esta etapa, admite sin aparente contradicción que la idea de progreso, germinada en el deseo, que en cuanto que afecto es más rudimentario que la facultad de la imaginación, condicione su fecundidad.

Bajo la tutela de esta razón aséptica, casi omnipotente, embriagadoramente seductora por su seguridad de planteamientos, tan propiamente ordenadora como inconscientemente creadora, proliferan los grandes relatos totalizadores, surgen una y múltiples nuevas realidades; la humanidad, por fin va definiendo un ámbito de actuación cada vez más arraigado en la naturaleza; todo es más cercano, más doméstico, en definitiva, más dominable; el ser humano se encumbra, es el gran protagonista de sus grandes relatos, todo parece obedecer a una coherencia lógica que enmudece cualquier objeción. Sin embargo, la imaginación, el mito, la ficción, siguen presentes en todos estos planteamientos de sentido. Tanto la creencia en un orden racional del universo, como la noción de un sentido (positivo) de la historia encarnada en la idea de progreso, y la necesidad de un valedor externo (Dios) que oriente a la vez que sea referente de la razón en los 
relatos emanados de ella, hacen pensar que las narraciones producidas en este lapso de tiempo no están carentes de producciones imaginarias, de ficciones cimentadoras.

La dinámica del pensamiento es imparable, no solo la del pensamiento creador o la del discursivo, también lo es la del pensamiento crítico, delator de discursos inacabados $u$ ocultadores de pensamientos que piensan lo pensado. La crítica pone a prueba los cimientos de los discursos totalizadores, centra su mirada en sus fundamentos y ahonda en las cuestiones fundamentales.

En el siglo XIX se revitalizará esta actitud y se pondrá en cuestión la existencia del gran referente, del garante, de la entidad fundamentadora de la totalidad y de la situación de privilegio del ser humano en el universo, y se promulgará su inexistencia, su muerte: "Dios ha muerto". A este grito se inaugura una nueva época del pensamiento, la actitud del humano se ve impelida a la modificación, todo debe ser humanizado, el ser humano queda como único referente de la totalidad y del mismo, los grandes relatos se resquebrajan, aunque el poder de su inercia hará que perduren en el tiempo al igual que perduran hoy día formas arcaicas de pensamiento. El mundo se humaniza, los valores, los referentes, los criterios, son radicalmente humanos.

En la ciencia se generan también enormes ámbitos de incertidumbre. Por vez primera desde su gran impulso en el Renacimiento, el optimismo científico se encuentra con abismos para los que no tiene respuestas, la des-ubicación racional es colosal, sus referentes newtonianos se derrumban. Los viejos postulados de la física clásica, aunque falsos, siguen siendo útiles para dar cuenta del entorno físico en el que nos desenvolvemos, prueba evidente de que la ficción es un medio perfectamente habitable incluso en un entorno puramente fáctico. Las grandes teorías científicas, aunque contradictorias unas con otras, siguen teniendo vigencia; el paradigma científico dominante adquiere doble carácter de interinidad, no solo el que le corresponde por definición propia, sino el de aquello que, cumpliendo con los requisitos de utilidad, se nos presenta incompatible con la verdad.

"La muerte de Dios" y la incertidumbre generada en la ciencia propician un estado de orfandad en el ser humano, de indigencia existencial, que lo obligan a parapetarse frente a los "elementos". Por un lado, la totalidad será colonizada por un imparable espíritu humanizador, todo será reducido a lo humano, a la perspectiva humana, a sus valores, a sus necesidades, todo estará al servicio de lo humano. La naturaleza, el universo, en cuanto que no humanos, se contemplarán con hostilidad. Por otro, el método científico será considerado el único procedimiento fiable de conocimiento, todo es susceptible de ser reducido a él, lo cognoscible es lo metódicamente reducido, primero a las síntesis perceptivas, después a las relaciones numéricas matemáticamente organizadas, finalmente a los experimentos racionalmente diseñados. Ambos procedimientos de ajuste, humanización de la totalidad y sometimiento de la totalidad a un 
método hegemónico (hipotético-deductivo), irán agrietando, debilitando y mermando la capacidad inercial de los grandes relatos que contemplarán cómo su hegemonía llega a su fin. Estos estallan en pedazos como un vidrio templado que se deja caer, el optimismo encarnado en la idea de progreso se ralentiza, la historia deja de tener un sentido claro, su finalidad es puesta en cuestión, la globalidad queda reducida al ámbito puramente mercantil y financiero, la totalidad se limita a la superposición de micro-relatos que intrínsecamente son fragmentarios por lo que no están sometidos a la exigencia de coherencia propia de los meta-relatos ilustrados, la razón desfallece como facultad privilegiada y creadora de totalidades explicativas. El signo devenido en símbolo se vuelve a manifestar como fundador de la realidad humana. Esta realidad es pura ficción emergida de la biología, pura ficción física, es realidad simbolizada.

En la nueva época, la postmodernidad, la capacidad imaginativa será puesta de nuevo a prueba; el universo se reduce a la intimidad que se cobija en el individualismo liberal y la fantasía cobra protagonismo cada vez menos camullada de concepto. La incredulidad y la renovada sospecha en relación a los grandes relatos determina el pensamiento crítico que no transige con las pretensiones totalitarias de estos y deambula elaborando metáforas sin ambición de trascendencia.

El pensamiento débil es el fruto de reconocer el agotamiento del anhelo de opinar que la realidad puede ser considerada al margen de lo humano, de la cándida creencia que las facultades del conocimiento no trasforman la realidad que conocen cuando se aproximan a ellas, que esta trasformación es de tal magnitud que adquiere la dimensión de acto creador que irremediablemente nos sumerge en una ficción que denominamos mundo en la medida en que en él podemos introducir un orden que facilita nuestra orientación y que retroalimenta la ilusión de dominio sobre un entorno sordo, opaco, indiferente, inconmensurable, sin sentido.

El lenguaje que durante siglos ha sido considerado un inocente instrumento de comunicación, un medio transparente e inocuo, sin influencia en el mensaje emitido, un simple utensilio del pensamiento, tan inofensivo como un búho a pleno día, se manifiesta ahora como el más poderoso de los agentes creadores de ficción; liberando al ser humano de la inmediatez del entorno, del yugo del presente, adentrándonos en el mundo de lo posible, de lo inmaterial, y proyectándonos a distintas dimensiones del espacio y el tiempo. Ahora, ese mismo lenguaje ha dejado de ser totalizador para convertirse en tan fragmentario como lo es el pensamiento de este período. Todo el conocimiento humano tiene un carácter puramente lingüístico; el mundo, el mundo humano, es una colosal metáfora, una manifestación lírica de las distintas sensibilidades y necesidades de este ser en su deambular por lo otro. Esta lírica ha contado y cuenta con la simulación de objetividad propia de todo espíritu invadido por la altivez primigenia y regularmente reforzada, provocada por la creencia de pertenecer a 
una especie superior y que la legitima para actuar con impunidad creadora. Una creación tal que impide al creador distinguirla de aquello que la contiene, que la posibilita, de la descomunal realidad que permanece imperturbable al pasajero espectáculo producido por la ciega embriaguez de una entidad biológica.

\section{FICCIÓN HUMANA - HUMANA FICCIÓN}

El lenguaje ha ido perfilando un mundo cada vez más habitable, más amable, que en muchos de sus ámbitos resulta ser hospitalario. La estructura íntima de la afabilidad mundana viene posibilitada por la reducción a criterios de orden arbitrariamente humanos que delimitan un horizonte ajeno al vértigo de lo que lo contiene. A este horizonte de sentido lo denominamos realidad, sin apercibirnos de que lo que le concede sentido es su arbitraria delimitación, y que precisamente esto es lo que esencialmente lo constituye como ficción. Una ficción, que aunque dominable, no está carente de enigmas, de interrogantes que la problematizan y que simultáneamente la envuelven de una verosimilitud que refuerza su sentido de realidad.

Píndaro, el poeta de poetas que compone cantos a los vencedores de los juegos, a la belleza de los efebos, que entiende el deseo como una marea incontenible, no creemos que sea un buen paradigma del pesimismo, del pensamiento de la penumbra, de la conciencia derrotada; sin embargo, o tal vez por ello, considera al hombre como el sueño de una sombra. Lejos, muy lejos de esta visión del heleno, se sitúa la idea del hombre como ser hegemónico capaz de ubicarse frente a una realidad bien definida, que le da sentido en cuanto que opuesto, $y$ cuyo emplazamiento frente a ella constituye el fundamento de toda su actividad creativa. No llegamos tan lejos como el poeta, que, en última instancia, no solo considera que la ficción es lo que caracteriza a la "realidad" humana, sino que el propio ser humano es ficción, sombra de una ficción, mímesis de una mímesis. Reconocemos que esta visión, tan inspiradora de cualquier forma de idealismo, es poesía, metáfora forjada a la luz de la conciencia de finitud que invade a cualquier ser humano que se sienta perteneciente a un todo tan inabarcable como el que nos contiene, pero no podemos dejar de reconocer que, como otras formas metafóricas, es tan sumamente inspiradora como para llevarnos a admitir que si ya la noción de "ser humano en el mundo" es problemática, lo es aún más el posible carácter real de sus producciones mentales.

Entender al ser humano, su mundo, de esta forma, no es el resultado de una visión pesimista, no nos posiciona como frustrados pensadores que un día, enardecidos por la esperanza y el ímpetu de juventud, confiamos que el cosmos en que nos sumergimos era tan límpido como el cristalino de un halcón y tiempo después se nos presentó tan impenetrable como un trópico inexplorado, no; lejos de esto, nuestra afirmación según la cual el mundo humano es ficcional responde a la convicción de que la ficción es mecanismo creado por el hombre para hacer habitable el desolado universo que nos acoge. 
